\title{
LINEAR IDENTIFICATION AND MODEL ADJUSTMENT OF A PEM FUEL CELL STACK
}

\author{
Kunusch C. ${ }^{(1,3)} \quad$ Husar A. ${ }^{(2)}$ Puleston P.F. ${ }^{(1,3)}$ Mayosky M.A. ${ }^{(1,4)} \quad$ Moré J.J. ${ }^{(1,3)}$ \\ (1) LEICI, Departamento de Electrotecnia, Universidad Nacional de La Plata, calle 1 esq. $47 \mathrm{~s} / \mathrm{n}, 1900$, \\ La Plata, Argentina. e-mail: ckunusch@ing.unlp.edu.ar \\ (2) IRI, Universitat Politècnica de Catalunya, c/ Llorens i Artigas 4-6, 08028, Barcelona, España. e- \\ mail: ahusar@iri.upc.edu \\ (3) Consejo de Investigaciones Científicas y Técnicas (CONICET), Argentina. \\ (4) Comisión de Investigaciones Científicas (CIC), Provincia de Buenos Aires, Argentina.
}

\begin{abstract}
In the context of fuel cell stack control a mayor challenge is modeling the interdependence of various complex subsystem dynamics. In many cases, the states interaction is usually modeled through several look-up tables, decision blocks and piecewise continuous functions. Many internal variables are inaccessible for measurement and cannot be used in control algorithms.

To make significant contributions in this area, it is necessary to develop reliable models for control and design purposes. In this paper, a linear model based on experimental identification of a 7-cell stack was developed.

The procedure followed to obtain a linear model of the system consisted in performing spectroscopy tests of four different single-input single-output subsystems. The considered inputs for the tests were the stack current and the cathode oxygen flow rate, while the measured outputs were the stack voltage and the cathode total pressure. The resulting model can be used either for model based control design or for on-line analysis and errors detection.
\end{abstract}

Keywords: PEMFC, spectroscopy, identification, MIMO linear model, experimental tests.

\section{INTRODUCTION}

Fuel cells (FC) are devices that convert hydrogen and oxygen electro-chemically into electrical energy and can be used in a wide variety of applications, from mobile and stationary power systems to portable appliances. The FC principles of operation were discovered in 1839 , but only during the past two decades has the research activity in this field increased dramatically, which has improved FC flexibility, reliability and cost [1]. One of the most influential factors that motivated FC development is the environmental impact of fossil fuels. Considering that hydrogen production from water can be performed using renewable energy such as solar, wind or geothermal, polymer electrolyte membrane fuel cells (PEMFCs) are emerging as one of the most promising alternatives to reduce fossil fuel dependency [1].

Improvements in this field require interdisciplinary work and development of new technologies in many areas. One of the most important issues is related to the development of robust control strategies dealing with disturbances and model uncertainties in a systematic way. For instance, to avoid transient power deterioration and irreversible damage to the FC, an effective control algorithm for oxidant stoichiometry regulation inside the cells during variable load tracking is required [2].

However, from the control point of view fuel cell stacks represent a major challenge due to their associated subsystems that reveal complex dynamics and conflicting control objectives. For example, in the cathode subsystem dynamics of a hydrogen-oxygen fed stack the states interaction is usually described through several look-up tables and decision blocks. Many internal variables are inaccessible and therefore cannot be measured, thus cannot be used in control algorithms [3]. Besides, there are measurable and non-measurable disturbances that affect the system operation, as well as uncertainties in the model parameters [4].

Therefore, to make significant contributions in this area, it is necessary to develop reliable models for control and design purposes. Thus, a dynamic linear model of a 7-cell stack experimentally obtained is presented. 


\section{MATERIALS AND METHODS}

\subsection{Fuel cell stack and test station}

The FC stack utilized is the EFC50-ST, which is a laboratory PEM fuel cell stack designed for the fundamental study of membrane electrode assembly (MEA) and fuel cell operation. This unit generates $50 \mathrm{~W}$ of power under normal operating conditions and can provide up to 100 W peak power [5].

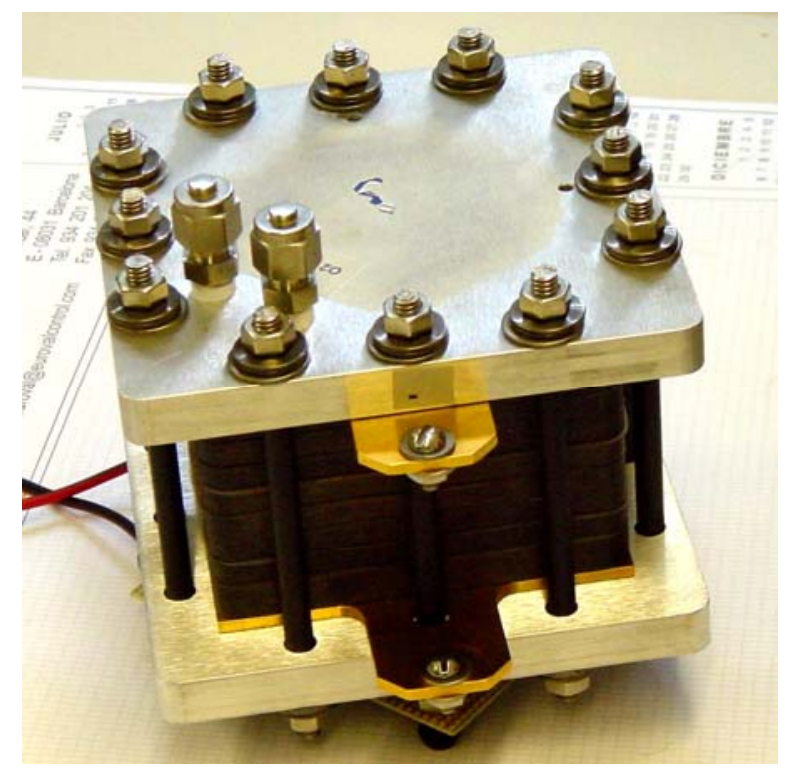

Figure 1: ElectroChem 7 MEA's stack (EFC50-ST)

The stack is an ElectroChem ${ }^{\circledR} 7$ cell stack with Nafion 115 MEA's, with a catalyst loading of 1 $\mathrm{mg} / \mathrm{cm}^{2}$ of platinum and Toray carbon fiber papers as gas diffusion layers, $50 \mathrm{~cm}^{2}$ of active area, 8 graphite plates, fittings, gold plated copper current collectors and individual cell voltage and temperature measurement points.

The power output of a single fuel cell is limited. Therefore, in order to raise the amount of power coming from the fuel cell, multiple cells are needed. Fuel cell stacks are multiple cells connected electrically in series, however the gas flows are connected in parallel.

The EFC50-ST can be operated at utilization levels for pure $\mathrm{H}_{2}$ and $\mathrm{O}_{2}$ close to $98 \%$. The nominal recommended pressure by ElectroChem ${ }^{\circledR}$ for hydrogen and oxygen gases is 3.44 bar.

The test station (figure 2) is constituted by two humidifiers and two heated gas transfer lines. The temperatures are controlled by a power station via decentralized PID controllers, allowing for independent gas conditions to the stack.

The gases flow rates are controlled by Bronkhorst $^{\circledR}$ EL-FLOW $^{\circledR}$ controllers with an operating range of 0.03-1.5 SLPM. In addition, the different pressures are measured by piezoresistive transmitters that have been designed for precision applications in industrial environments for pressures ranging from 0.2 to 6 bar. Finally, the AC-impedance measurements were performed by making use of the electronic load TDI RLB488 Dynaload $^{\circledR}$, in conjunction with the HP-35760A spectrum analyzer.

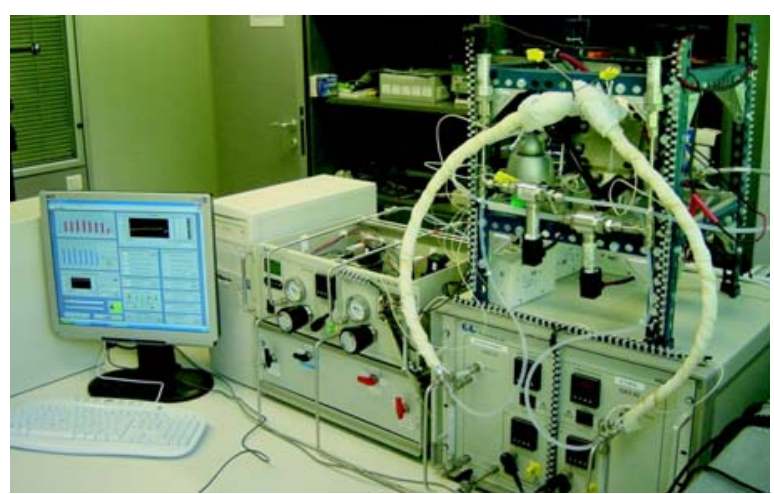

Figure 2: Fuel cell test bench at IRI (UPC)

\subsection{Operation range}

The first step to perform a dynamic linear model of the fuel cell system is to set the operating range. To this end, the stack temperature was set to $60^{\circ} \mathrm{C}$ and the humidifiers temperatures were fixed at $50{ }^{\circ} \mathrm{C}$, so the relative humidity inside the cells was $65 \%$. The corresponding line heaters for the anode and cathode sides were both set to $60{ }^{\circ} \mathrm{C}$. The anode and cathode nominal pressure was set to the recommended value of 3.44 bar, while the average current was 5 A. Finally, the hydrogen average flow rate was 1.5 SLPM and the oxygen average flow rate was 0.5 SLPM, thus the resulting stoichiometries of the stack were $\lambda_{a n}=$ 5.63 and $\lambda_{c a}=3.77$.

\subsection{Spectroscopy tests}

The procedure followed to obtain a linear model of the system consisted of performing spectroscopy tests of four different single-input single-output subsystems. A spectroscopy test is based on exciting a dynamic system through sinusoidal signals of different frequencies. Then, after processing the resulting output data, a frequency diagram of the system response (Bode, Nyquist, Nichols, etc.) can be generated. Afterwards, different linear systems can be fitted to the data in order to develop a complete representative model. This well known frequency based tests are rather useful to develop accurate linear models off-line [6-7]. 
In this paper, four different identification tests were performed. The inputs were the stack current $\left(I_{s t}[\mathrm{~A}]\right)$ and the cathode flow rate $\left(w_{c a}\right.$ [SLPM]), while the measured outputs were the stack voltage $\left(V_{s t}[\mathrm{~V}]\right)$ and the cathode inlet pressure $\left(p_{c a}[\mathrm{bar}]\right)$.

The following subsections describe the technical specifications of the tests, as well as the corresponding results.

\subsubsection{Test 1: $V_{s t}(s) / I_{s t}(s)$ submodel}

Performing impedance measurements on fuel cells can assist in identifying problems within the fuel cells components, as well as track troubles in the fuel cell assembly process. More specifically, such measurements can be helpful in identifying the kinetic and ohmic resistances of the FC stack, the electrolytic and the transport limitations of the reactants.

By imposing a sinusoidal perturbation in the stack current and measuring both the perturbed current and the voltage response, the $\mathrm{AC}$ impedance can be calculated. Repeating this procedure at different frequencies, an electrochemical impedance spectroscopy can be obtained. This test has been performed in the stack considering a frequency range from $100 \mathrm{mHz}$ to $1 \mathrm{KHz}$, a mean stack current of $5 \mathrm{~A}$ and $1 \mathrm{~A}$ amplitude, with a constant cathode flow rate of 0.5 SLPM.

The relationship between the stack current and the stack voltage is modeled through a transfer function, which is depicted by a Bode diagram in figure 3 .

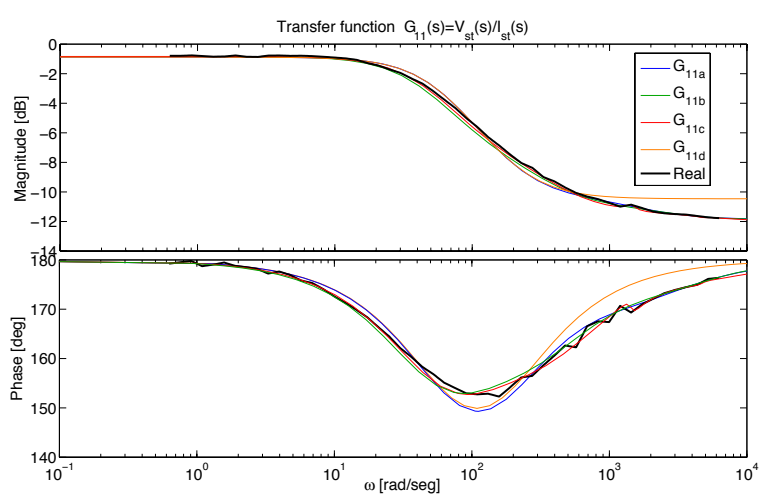

Figure 3: Different identification models of $G_{11}(s)=V_{s t}(s) / I_{s t}(s)$

After obtaining the data, a parametric identification was conducted in order to fit the results to several linear time invariant (LTI) systems, as shown in figure 3. Some approximations and order reductions were made taking into account the existing tradeoff between model complexity and its accuracy to the real data. The best approximations were obtained fitting the raw data to parametric Output Error (OE) models through the least squares method. Among them, the most accurate model found for the $V_{s t} / I_{s t}$ subsystem was:

$$
G_{11}(s)=V_{s t}(s) / I_{s t}(s)=\frac{-0.29971(s+189)}{(s+62.71)}
$$

\subsubsection{Test 2: $V_{s t}(s) / w_{c a}(s)$ submodel}

Another subsystem modeled was the dynamics between the cathode flow rate of oxygen and the resulting stack voltage generated at a given current. In this case, for the spectroscopy test, an oxygen flow rate sinusoidal perturbation was introduced to the system, while the stack current was set constant, at $5 \mathrm{~A}$. The cathode flow rate frequency range was $10 \mathrm{mHz}$ to $10 \mathrm{~Hz}$, and using a mean value of 0.5 SLPM and an amplitude of 0.815 SLPM.

Several LTI models where fitted to the experimental data and the results are plotted in the Bode diagram in figure 4.

Finally, the most accurate model obtained to fit the subsystem was:

$$
G_{12}(s)=V_{s t}(s) / w_{c a}(s)=\frac{0.023957}{(s+12.96)(s+0.1683)}
$$

It is important to note that after the analysis it was found that the practical range of application where equation (2) accurately describes the $V_{s t}(s) / w_{c a}(s)$ submodel is from 0 to $1 \mathrm{rad} / \mathrm{sec}$.

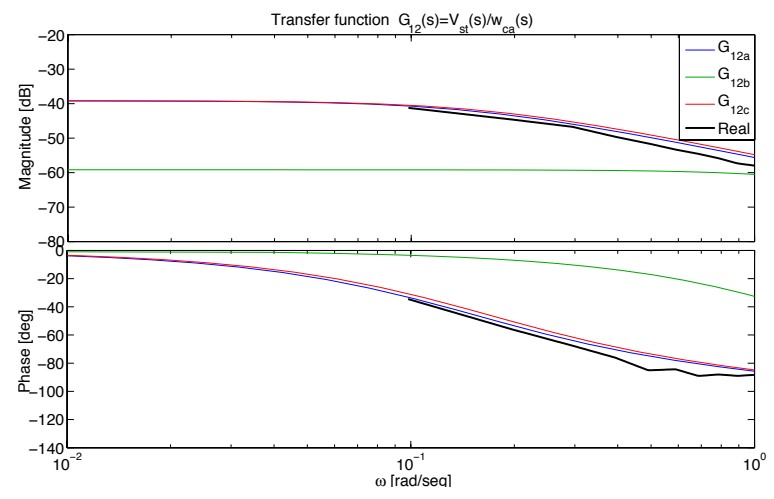

Figure 4: Different identification models of

$$
G_{12}(s)=V_{s t}(s) / w_{c a}(s)
$$

\subsubsection{Test 3: $p_{c a}(s) / I_{s t}(s)$ submodel}

Another significant output to analyze is the inlet pressure of the cathode. The analysis of the $p_{c a}$ behavior is a very important issue when a turbo compressor is connected to feed the stack, because it directly affects the voltage of the FC due the change in oxygen concentration. 
A stack current sinusoidal perturbation was added to identify this subsystem dynamics in the settled operating range. The sinusoidal signal had a mean value of $5 \mathrm{~A}$ and an amplitude of $1 \mathrm{~A}$, and its frequency ranged from $10 \mathrm{mHz}$ to $10 \mathrm{~Hz}$. The cathode flow rate was set constant at 0.5 SLPM.

In this particular stack, because of its open flow field design and the high inlet pressure, the pressure variation as a result of current change was rather small. Therefore, the signal to noise ratio of $p_{c a}$ measure was poor, turning this test difficult to be conducted. However, some acceptable data was recorded and some representative models were obtained (figure 5). Among them, the most simple and accurate was the following:

$$
G_{21}(s)=p_{c a}(s) / I_{s t}(s)=\frac{-0.0079596}{(s+0.003619)}
$$

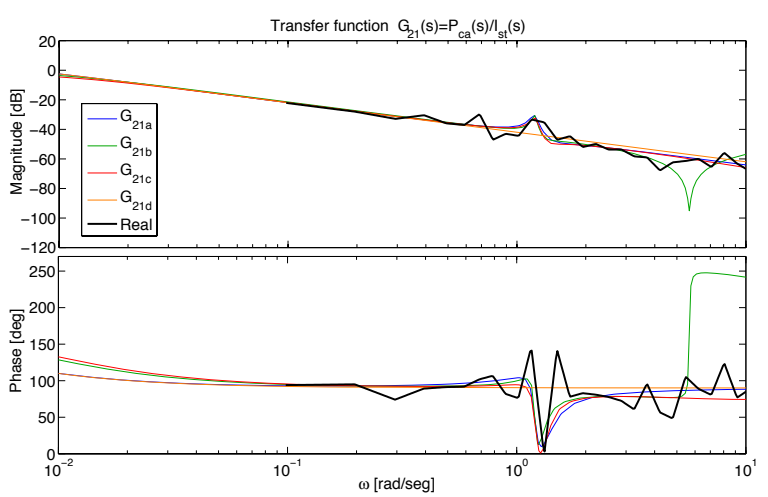

Figure 5: Different identification models of $G_{21}(s)=p_{c a}(s) / I_{s t}(s)$

Note that in other stacks the pressure drop due to currents changes could be more significant. Thus, the signal to noise ratio would be higher and this procedure can retrieve more accurate results.

\subsubsection{Test 4: $p_{c a}(s) / w_{c a}(s)$ submodel}

Finally, the last subsystem to be identified is the corresponding flow-pressure cathode dynamics. The raw data of this model was also obtained via a spectroscopy test and then fitted to a suitable LTI model. The stack current was set constant at $5 \mathrm{~A}$ and the considered frequency range of the cathode flow rate sinusoidal perturbation was $10 \mathrm{mHz}$ to $10 \mathrm{~Hz}$, with a mean value of 0.5 SLPM and amplitude of 0.815 SLPM (see the results for different fits in figure 6).

The most accurate model found for this subsystem was:
$G_{22}(s)=p_{c a}(s) / w_{c a}(s)=\frac{0.041573}{(s+3.408)(s+0.1683)}$

Similarly to the transfer function in equation (2), the experiments showed that the valid range of equation (4) is 0 to $1 \mathrm{rad} / \mathrm{sec}$.

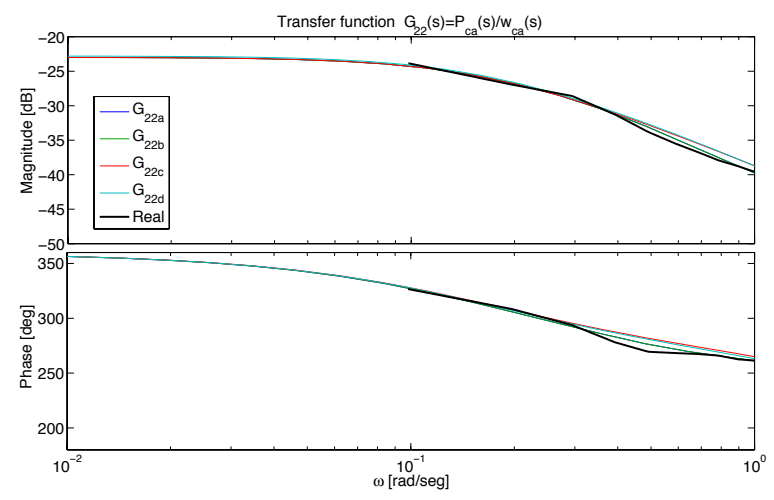

Figure 6: Different identification models of $G_{22}(s)=p_{c a}(s) / w_{c a}(s)$

\section{SPECTROSCOPY RESULTS}

\subsection{Final model}

Gathering the results from section 2.3, a representative multi-input multi-output (MIMO) model of the system was obtained (figure 7). The resulting linear model can be expressed as follows through four coupled single-input single output (SISO) systems that relate the different channels.

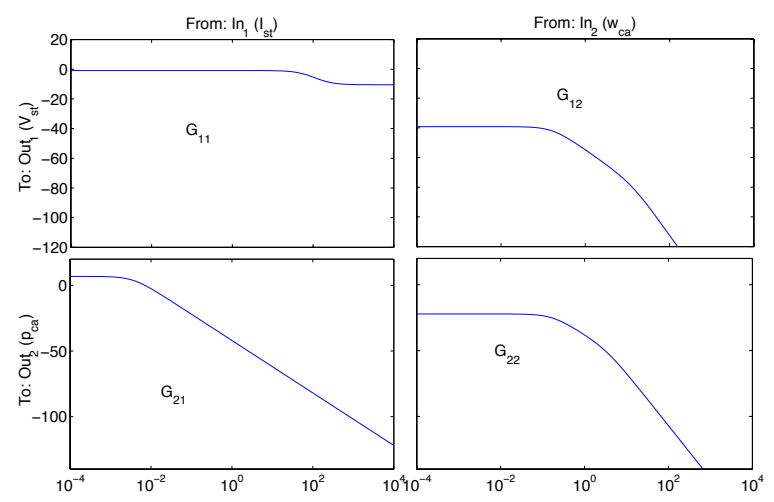

Figure 7: Input-Output Bode diagrams

Furthermore, its minimal state-space realization can be denoted by the following expression:

$$
\begin{aligned}
& \dot{x}=A x+B u \\
& y=C x+D u
\end{aligned}
$$


$A=\left[\begin{array}{ccccc}-0.003619 & 0 & 0 & 0 & 0 \\ 0 & -12.956 & 5.8495 & 0 & 7.7055 \\ 0 & 0 & -39.847 & 0 & 30.121 \\ 0 & 0 & 7.7055 & -3.408 & 10.151 \\ 0 & 0 & 30.121 & 0 & -23.034\end{array}\right]$

$B=\left[\begin{array}{cc}0.089216 & 0 \\ 0 & 0 \\ 4.8996 & 0.038696 \\ 0 & 0 \\ -3.7194 & 0.050974\end{array}\right]$

$C=\left[\begin{array}{ccccc}0 & 0.038696 & -4.8996 & 0 & 3.7194 \\ -0.089216 & 0 & 0 & 0.050974 & 0\end{array}\right]$

$D=\left[\begin{array}{cc}-0.29971 & 0 \\ 0 & 0\end{array}\right]$

Note that the proposed model can be used for control design, engineering analysis and prediction purposes.

\section{SIMULATIONS}

In the effort to fit detailed experimental results into a comprehensive model of the fuel cell stack, the following proposed computer model was used to run the simulations (see figure 8). Note that the models of section 2.3 correspond to differential LTI systems at the specified operation point, so the mean value of each input and output must be included in the simulation model. In addition, the models in section 2.3 were directly obtained from the raw data, therefore the sensors gains values have to be also added to make the simulations physically representative.

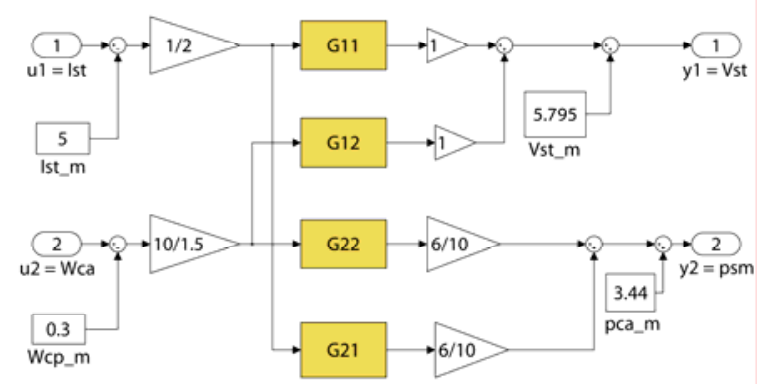

Figure 8: Simulink model of the stack

The resulting model shows the typical dynamic behavior of 7-cell stack working in the given operating point. Thus, it can be used for control design purposes as well as for analytical studies and for parameters identification.

Finally, figure 9 shows the changes in stack voltage and the cathode pressure when the two different inputs, namely the stack current $\left(I_{s t}\right)$ and the cathode air flow rate $\left(w_{c a}\right)$ are excited. In addition, it shows the sensibility of the system when additive disturbances are present in the inputs $(300 \mathrm{sec}$. to $600 \mathrm{sec}$.).
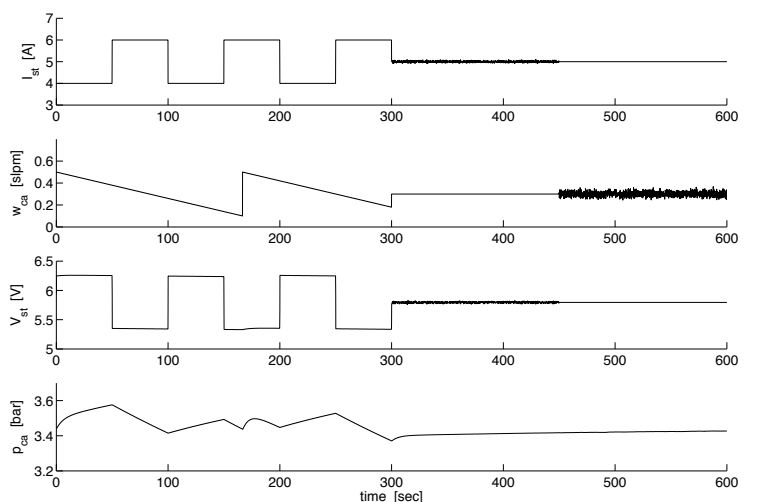

Figure 9: Simulation results

\section{CONCLUSIONS}

A fuel cell system is complex and all phenomena involved in the process are difficult to be described. However, under certain assumptions based on the fuel cell operation, a MIMO linear model based on experimental spectroscopy tests considering was developed in this paper. The proposed model represents the dynamic behavior of a hydrogen-oxygen PEM 7cell stack, when humidity and temperature are kept controlled.

The simulations exhibit the dynamics in the neighborhood of the operation point when additive disturbances are added to the inputs. This resulting MIMO model provides an accurate behavior and can be used either for model based control design or for on-line analysis and errors detection.

Based on these results it is foreseen to continue working to develop an extended model of the system (i.e. considering more subsystems) at different working conditions.

\section{ACKNOWLEDGMENTS}

This research has been funded by the Agencia Española de Cooperación Internacional (AECI), Universidad Nacional de La Plata (UNLP), Universitat Politècnica de Catalunya (UPC), Consejo de Investigaciones Científicas y Técnicas (CONICET) and the Ministerio de 
Educación y Ciencia (MEC) of Spain under the contract DPI2007-62966.

\section{REFERENCES}

[1] J. Larminie and A. Dicks. "Fuel Cell Systems Explained". John Wiley \& Sons Inc., second edition, 2003.

[2] C. Bao, M. Ouyang, B. Yi "Modeling and control of air stream and hydrogen flow with recirculation in a PEM fuel cell system-I. Control-oriented modeling". International Journal of Hydrogen Energy, vol 31, issue 13, october 2006, pp. 1879-1896.

[3] J.T. Pukrushpan, A.G. Stefanopoulou, and H. Peng. "Control of Fuel Cell Power Systems". Springer, London, 2004.

[4] C. Kunusch. "Second order sliding mode control of a fuel cell stack using a twisting algorithm". Master's thesis, Electrical Department, National University of La Plata., March 2006.

[5] ElectroChem Inc website: http://www.fuelcell.com/pdfs/FuelCellStack .pdf (accessed May 2006).

[6] X. Yan, M. Hou, L. Sun, D. Liang, Q. Shen, H. Xu, P. Ming, B. Yi "AC impedance characteristics of a $2 \mathrm{~kW}$ PEM fuel cell stack under different operating conditions and load changes". International Journal of Hydrogen Energy, vol 32, issue 17, december 2007, pp. 4358-4364.

[7] C. M. Lai, J. C. Lin, K. L. Hsueh, C. P. Hwang, K. C. Tsay, L. D. Tsai, Y. M. Peng "On the electrochemical impedance spectroscopy of direct methanol fuel cell". International Journal of Hydrogen Energy, vol 32, issue 17, december 2007, pp. 4381-4388. 